\title{
Risks and Difficulties of the Project
}

How to remember Italian Fascism seems to be a persisting problem for Italians. The idea of creating a museum in Predappio looks, on the face of it, an excellent way of confronting the problem. However, in my view, there are difficulties. The first is the proposed place of the museum. It is impossible to have a museum relating to Fascism in Predappio without creating some kind of monument to the Duce. People will inevitably ask: Why do we have the museum here? And the answer, equally inevitably, has to be: Because this is the place where HE was born. Thus the figure of the fascist leader is given pride of place and, to some extent, glorified; what Fascism did, as a regime, is pushed to the background. The mayor of Predappio may have his very justified reasons for wanting to change the nature of the way people visit the town and discourage fascist revivalists but it is to be doubted that a museum is the best method od achieving his ends. Are the neo-blackshirts going to be impressed by a few show cases relating to the $1920 \mathrm{~s}$ and the 1930s and desist from their unruly marches? It seems unlikely. On the contrary, the more Predappio is related to Fascism, the more marchers there are likely to be, and the shopkeepers are not going to lose the opportunity to stock even more fascist memorabilia.

The second problem relates to the declared intention of "putting the 1920s and 30s back into the history of Italy" and not seeing the two decades exclusively in the light of the regime. The proposal asks for detachment, for a calmer vision of this particular past - a vision no longer dominated by the compulsion for moral and political condemnation. These are, in many ways, laudable intentions - but there 
are immense risks. Many of these risks were evident in the exhibition in Rome in 1987 which purported to be about Fascism but managed to give the impression that the ventennio had been all about successful modernization, thus implicitly portraying the regime in a favourable light. The problem for any museum is: what do you show and how do you show it? Certainly, simple denunciation is not a useful approach - we do not want another "House of Horror" on the Budapest model - but neither is deliberate avoidance of any kind of moral position, which in fact cannot be absent when decisions, necessarily selective, are made about what to display. The fascist regime was very good at its own self-representation - we are all familiar with the Istituto Luce films of enthusiastic adunate oceaniche - and a big risk is that much of this will filter through into the museum simply because the material relating to fascist "realisations" is often very attractive. Exhibits are likely to show sectorial development - improvements in child care, for instance, through the efforts of the Onmi, or children at the summer colonie - which are part of the modernising thrust of interwar Italy, but the risk is that the observer goes away with the "Mussolini did many good things" impression - a concession far too common and one we don't make in respect of our judgments on Hitler and Stalin, who also "did many good things". Indeed, to be seriously useful, a museum of this kind should have an international comparative aspect. Yes, there were more tractors in agriculture in Italy during the 1930s; nonetheless Italian soldiers sent to the Ukraine in 1941 were amazed by the extent of Soviet modernisation in agriculture, much greater than that realised in Italy during the same period. Here it would be necessary to show that, under Fascism, Italy made some progress in the direction of modernisation, but did less and did what it did less well than other countries, perhaps because of the social and economic priorities of Fascism - a complex historical question not easy to show in museum terms. This relates to the questions of what you show and how you show it - perhaps not insuperable but certainly difficult to resolve; that "detached" historical analysis can be realised in respect of the period 1919-1945 without the intrusion of some kind of moral criterion in the treatment of the main feature of those years - Fascism - seems to me to be an illusion. However, my main reservations about a museum of the fascist period are related more to what cannot be shown in physical terms. This involves questions of subjectivity and is closely linked to my own particular view of how this kind of regime operates (obviously there many other ways of considering the regime). Totalitarian/authoritarian regimes such as the fascist regime function on a mixture of consensus and coercion. For the majority of the population, the apparent consensus is conceded within the overall context of coercion. In other words, and very briefly, people operate within a context of 
caution and fear. After the first half of the 1920s this is not so much fear of open and explicit physical violence; it is fear of what could happen if you step out of line, if you annoy the authorities in some way, or if your enemy achieves a position of command. This applies for the whole period of the regime, including the famous anni del consenso. The regime can hurt you in myriad indirect ways if it wants to and you have no redress. You might lose your job, your license for your shop, your invaluable tessera del partito/pane; your family might suffer (for example, during the 1930s Fiat took on workers through the filter of the local party organization; offend the party and your son doesn't get a job); you might be denied a pension or the assistance for the poor offered by fascist "solidarity". In other words, the normal interactions of civil society were very often determined, in the final analysis, by political criteria and the characteristic of these criteria was extreme discrezionalità - again something very difficult to show in museum terms. This context of what might be called the implicit violence of rigid social control is very difficult to portray in such a way as to render fully any idea of the extent to which it operated, precisely because it remains an implicit, unspoken, conditioning context. A few schede indicating discrimination on the basis of political criteria will not make the point with sufficient strength; even a room relating to the workings of the Tribunale Speciale can only suggest specific repression of an exiguous minority. Nor is it easy to illustrate the conformism that the context of fear induces. This is the real problem with a museum relating to Fascism. Tractors look good, large areas of reclaimed land look wonderful; healthy babies are irresistible; fear and fear-induced caution are much more difficult to communicate in visual terms.

Finally, it is probably worth saying that I think there should be some kind of museum relating to Fascism and the fascist period. This should instruct and illustrate what Fascism had meant for Italy and Italians and should aim to "conserve" this memory for future generations. Put like this, it sounds simple, but it is not. Some of the problems relating to such a project are outlined above. Perhaps a greater, and more fundamental, problem is represented by the fact that historians are still very far from agreeing on their assessment of Fascism and, in particular, on the nature of the relationship between the regime and the population. And if the historians are not agreed, the task confronting the museum curator in creating what is, in any case, bound to be a selective memory, becomes almost insuperable. 